\title{
TRADISI PUTER KAYUN DI BANYUWANGI DALAM UPAYA MEMPERINGATI NAPAK TILAS JEJAK KI BUYUT JAKSO
}

\author{
Aprin Susanto $^{1}$, Dhalia Soetopo ${ }^{2}$ \\ Fakultas Keguruan dan Ilmu Pendidikan, Universitas PGRI Banyuwangi \\ Email: Aprinsusanto@gmail.com \\ Email: dhalia.soetopo@gmail.com
}

\begin{abstract}
Puter Kayun merupakan tradisi yang dilakukan warga Boyolangu saat memasuki hari ke-10 Bulan Syawal. Warga berkumpul lalu bersama-sama menaiki dokar (kereta kuda) hias bersamasama menuju Pantai Watudodol yang jauhnya $15 \mathrm{~km}$. Tradisi ini diawali dari perkampungan Boyolangu. Beragam dokar hias tampak berderet-deret. Dokar-dokar ini adalah milik warga Boyolangu yang masih memegang adat Puter Kayun. Tradisi ini terus digelar sebagai napak tilas jejak Ki Buyut Jakso, leluhur warga Boyolangu yang dipercaya sebagai orang yang pertama kali membangun jalan di kawasan utara Banyuwangi.
\end{abstract}

\section{Keywords : Tradisi Puter Kayun, Napak Tilas, Jejak Ki Buyut Jakso}

\begin{abstract}
Puter Kayun is a tradition carried out by the people of Boyolangu when entering the $10^{\text {th }}$ day of the month of shawwal. Residents clumped together and together climbed the horse carriage (horse carriage) in ornament together to watudodol beach which was $15 \mathrm{~km}$ away. This traditional begins with the Boyolangu village. A variety of ornament chariots appeared in rows. This is owned by residents of Boyolangu who still hold the custom of puter kayun. This traditional continues to be heldas the trail of trace ki great grandchild jakso, ancestor of Boyolangu citizen who believed to be the first person to build a road in the northern region of Banyuwangi.
\end{abstract}

Keywords : Tradition Puter Kayun, the trail of trace ki great grandchild jakso

\section{Pendahuluan}

Kabupaten Banyuwangi selain menjadi

perlintasan dari Jawa ke Bali, Juga merupakan daerah pertemuan berbagai jenis kebudayaan dari berbagai wilayah. Budaya masyarakat banyuwangi diwarnai oleh budaya Jawa, Bali, Madura, Melayu, Eropa, Tionghoa dan budaya lokal yang saling mengisi dan akhirnya menjadi tipikal yang tidak ditemui di wilayah manapun di Pulau Jawa. 
Masyarakat Using Banyuwangi memiliki banyak tradisi di Bulan Syawal. Selain Seblang, Barong Ider Bumi, setiap usai lebaran ada tradisi Puter Kayun. Puter Kayun adalah tradisi napak tilas masyarakat Using Boyolangu, Kecamatan Giri Banyuwangi dengan cara beramai-ramai naik delman. warga setempat dahulu menjadi pusat kusir dokar. Sehingga, saat puter kayun selalu menggunakan armada dokar. Namun, belakangan, dokar mulai tersisih. Bahkan, kini hanya tinggal 10 unit.

Dahulu, lebih dari 50 unit. Meski begitu, warga tetap mempertahankan tradisi menggunakan dokar. Kini, warga yang bertahan sebagai kusir dokar tak lagi sebagai angkutan umum, tapi dokar wisata. Ritual puter kayun ini sudah menjadi salah satu agenda pariwisata di Banyuwangi. Tak hanya warga lokal, sejumlah wisatawan asing ikut memeriahkan tradisi ini.

Disetiap tahun, pada 10 Syawal atau 10 hari sesudah perayaan Lebaran Idhul Fitri, warga Desa Boyolangu, Kecamatan Giri, Banyuwangi mengajak seluruh anggota keluarganya berpawai menggunakan dokar yang dihias warna-warni menuju ke Pantai Watu Dodol. Warga setempat menyebutnya sebagai tradisi Puter Kayun.

Puter Kayun adalah salah satu tradisi unik yang sampai saat ini masih dilestarikan masyarakat Using di Desa Boyolangu, Kecamatan Giri, Kabupaten Banyuwangi. Puter Kayun merupakan tradisi yang dilakukan setiap tujuh sampai sepuluh hari setelah lebaran Idul Fitri.

Tradisi unik ini merupakan napak tilas pembangunan jalan dari PanarukanBanyuwangi. Napak tilas itu dilakukan dengan menunggang Dokar atau Andong. Di Boyolangu, tradisi Puter Kayun sudah diwariskan secara turun-temurun. Selain sebagai ungkapan rasa syukur atas rejeki Tuhan, Puter Kayun juga merupakan sebuah tradisi menepati sebuah janji, mereka adalah keturunan Buyut Jaksa atau Ki Martajaya. Konon, Buyut Jaksa yang tinggal di Bukit Silangu adalah seorang yang sangat sakti. Ia adalah orang yang berjasa dalam pembangunan jalan dari Panarukan hingga Banyuwangi di masa Kolonial Belanda. Namun usaha pembuatan jalan tersebut terhenti karena menemui rintangan. 
Rintangan tersebut adalah bukit batu yang keras dan tebal, sehingga tidak terusik sedikitpun oleh kekuatan manusia. Terlebih lagi dibukit itu diyakini ada kekuatan gaib. Tiap hari korban pun berjatuhan dari pihak Pribumi.

Tradisi yang digelar secara turun temurun setiap lebaran tersebut sebagai ungkapan syukur atas rezeki yang telah diberikan Tuhan, mempererat tali silaturahmi keluarga, sekaligus melakukan napak tilas dari para leluhur warga setempat yang membuat jalan dari Boyolangu menuju Pantai Watu Dodol yang berjarak 15 kilometer.

\section{Kajian Literatur dan} pengembangan Hipotesis

- Tradisi puter Kayun

Puter Kayun adalah tradisi napak tilas masyarakat Using Boyolangu, Kecamatan Giri Banyuwangi dengan cara beramai-ramai naik delman. Ritual ini digelar satu tahun sekali, tepatnya hari ke-10 bulan Syawal. Ratusan warga ini mengendarai dokar (delman) dari Kelurahan Boyolangu menuju Pantai Watu Dodol sejauh lima belas kilometer. Sebelum pelaksanaan puter kayun, tradisi ini diawali sejumlah ritual. Dimulai dari tradisi kupat sewu (seribu ketupat) yang digelar tiga hari sebelum puter kayun. Dalam kupat sewu ini, masyarakat Boyolangu membuat ketupat, lepet dan makanan lain sebagai pelengkap. Tiap rumah membuat kupat dan lepet untuk dibagi-bagikan kepada tetangga dan saudara. Selain dibagikan ketupat ini juga untuk selamatan yang digelar disepanjang jalan desa. Tradisi ini terus digelar sebagai napak tilas jejak Ki Buyut Jakso, leluhur warga Boyolangu yang dipercaya sebagai orang yang pertama kali membangun jalan di kawasan utara Banyuwangi.

\section{- Napak Tilas}

Napak berasal dari kata tapak yaitu bekas kaki sedangkan tilas artinya bekas dari seseorang. menurut KBBI Napak Tilas yaitu "Berjalan kaki dengan menelusuri jalan yang pernah dilalui oleh seseorang, pasukan, dan sebagainya untuk mengenang perjalanan pada masa perang dan atau sejarah masa lalu".

Kegiatan Napak Tilas umumnya ditujukan kepada generasi-generasi muda Indonesia, bertujuan untuk mendidik generasi muda umumnya untuk mengingat, meneruskan 
dan mewariskan nilai-nilai perjuangan para pahlawan, mengingat generasi muda tidak mengalami langsung perjuangan bangsa dalam merebut dan menegakkan kemerdekaan dan kedaulatan Bangsa Indonesia.

\section{METODE PENELITIAN}

\subsection{Pendekatan Dan Jenis Penelitian}

Pendekatan masalah yang digunakan dalam penelitian ini adalah menggunakan pendekatan kualitatif. Pendekatan kualitatif adalah metode penelitian yang memusatkan perhatiannya pada prinsip-prinsip umum yang mendasar perwujudan satuan-satuan gejala yang ada dalam kehidupan sosial manusia. Penelitian kualitatif merupakan proses penelitian yang bertujuan memahami suatu masalah kemanusiaan yang didasarkan pada penyusunan suatu gambaran yang kompleks dan menyeluruh menurut pandangan yang rinci dari para informan serta dilaksanakan di tengah setting alamiah. Basrowi dan Suwandi (2008:1) menyatakan bahwa penelitian kualitatif adalah salah satu prosedur penelitian yang menghasilkan data deskriptif berupa ucapan atau tulisan dan perilaku orang-orang yang diamati.
Penelitian kualitatif adalah penelitian yang pemecahan masalahnya dilakukan dengan menggunakan data empiris.

Jenis penelitian yang digunakan dalam penelitian ini adalah jenis studi kasus. Studi kasus adalah suatu pendekatan untuk mempelajari, menerangkan, atau menginterpretasi suatu kasus dalam konteksnya secara natural tanpa adanya intervensi dari pihak luar. Jenis penelitian ini akan segera berlaku jika terdapat pertanyaan mengenai bagaimana (how) dan mengapa (why). Kecenderungan dalam studi kasus ini adalah bahwa studi ini berusaha untuk menyoroti suatu keputusan atau seperangkat keputusan, dan mengapa keputusan tersebut diambil, bagaimana pelaksanaannya, dan apakah hasilnya.

Alasan digunakannya jenis penelitian studi kasus adalah karena metode penelitian yang digunakan merupakan metode penelitian deskriptif, dimana metode kualitatif ini dalam pelaksanaannya dapat dilakukan melalui studi kasus maupun studi komparasi. Berdasarkan hal tersebut, jenis penelitian studi kasus ini dipilih juga karena sifat kecenderungannya yang biasa memperhatikan permasalahan mengenai 
mengapa suatu kebijakan diambil dan bagaimana pelaksanannya.

\section{Hasil dan Pembahasan}

Ritual Puter Kayun digelar satu tahun sekali, tepatnya hari ke-10 bulan syawal. Ratusan warga ini mengendarai dokar (delman) dari kelurahan Boyolangu menuju Pantai Watu dodol sejauh lima belas kilometer. Belasan Dokar-dokar tersebut dihias aneka bunga cantik dan beragam asesoris yang menarik, layaknya andong wisata. Dokar-dokar ini adalah milik warga Boyolangu yang memang masih memegang adat Puter Kayun.

Sambil dokar berjalan, seluruh masyarakt Boyolangu berdiri mengiringi dokar-dokar di sepanjang jalan yang menjadi rute puter kaun. Sampai di urutan dokar terakhir, masyarakt pun bergegas mengikuti rombongan dokar-dokar ini hingga di pantai watu dodol. Setelah sampai di Pantai watu dodol, masyarakat juga menggelar selamatan dengan makan bersama di sepanjang pantai sebagai ungkapan rasa syukur atas rejeki yang mereka dapatkan selama setahun terakhir.

Adapun rute yang dilalui parade delman ini menyusuri jejak dari lelhurnya, Ki Buyut
Jakso. Dahulu membuka jalan di sebalah utara, Belanda meminta bantuan pada $\mathrm{Ki}$ Buyut Jakso karena bagian utara ada gundukn gunung yang tidaak bisa dibongkar. Ki Buyut Jakso lalu bersemedi dan tinggal di Gunung Silangu yang sekarang jadi Boyolangu. Atas kesaktiannya, akhirnya bisa membuka jalan tersebut hingga wilayah itu diberi nama Watu Dodol yang artinya watu didodol (dibongkar).

Ki Buyut Jakso berpesan agar anak cucu keturunannya berkunjung ke Pantai Watu dodol untuk melakukan napak tilas apa yang telah dilakukannya. Sebelum pelaksanaan puter kayun, tradisi ini diawali sejumlah ritual. Dimulai dari tradisi kupat sewu (seribu kupat) yang digelar tiga hari sebelum puter kayun. Dalam kupat sewu ini, masyarakat Boyolangu membuat ketupat, lepet dan masyarakat lain sebagi pelengkap. Tiap rumah membuat kupat dan lepet untuk dibagi-bagikan kepada tetangga dan saudara. Selain dibagikan ketupat ini juga untuk selamatan yang digelar disepanjang jalan desa.

Warga menggelar tikar di depan rumah masing-masing dan menyajikan kupat. Jika dihitung, ada lebih seribu kupat yang 
disajikan dalam selamatan ini. Tujuannya agar warga selamat dan diberi rejeki yang berlimpah serta terbebas dari musibah. Dengan arak-arakan beragam budaya mengelilingi kampung. Mulai dari tapekong, kebo-keboan, kuntulan, barong ondel-ondel, gandrung, hadrah dan patrol semua ditampilkan. Rangkaian berikutnya, masyarakat berziarah ke makam buyut Jakso yang ada di Boyolangu, lalu dilanjutkan dengan tradisi Puter Kayun.

\section{Kesimpulan}

Jadi Tradisi Puter Kayun sudah dilaksanakan sejak lama. Awal dulu ceritanya, ada Buyut Jokso. Makamnya ada di Boyolangu. Dia salah satu tokoh pada zamannya Mas Alit, bupati pertama, dia itu yang bisa mendodol gunung batu ini. Gunung yang saat ini bernama Watu Dodol ini, bila dilihat sebelum didodol (dibuka), memang menghalangi akses jalan dari Banyuwangi ke Panarukan (Situbondo). Karena kesulitan membongkar, pemerintah Kolonial Belanda, kemudian menyuruh Mas Alit (Bupati pertama Banyuwangi) untuk mencari cara bagaimana membongkar bagian gunung yang menghalangi proyek jalan tersebut. Pembongkaran Gunung Watu
Dodol, dipercaya baru bisa dibongkar oleh warga Boyolangu melalui mediasi Buyut Jokso. Gunung tersebut baru bisa dibongkar dengan beberapa syarat. Salah satunya, harus datang dan memberi upacara selamatan tiap tahun. Dari situ, muncullah tradisi Puter Kayun.

\section{Refrensi}

Basrowi \& Suwandi. (2008). Memahami Penelitian Kualitatif. Jakarta: Rineka Cipta. Alwasilah. 2006. Ilmu Pelestarian Budaya. Bandung: RinekaCipta.

KamantoSunanto, 1999. Proses Pewarisan Budaya Dalam Masyarakat.Bandung:

Alfabeta

Yoeti Oka, (1985). Budaya Tradisi Yang Hampir Punah: Bacaan Populer Untuk Perguruan Tinggi Jakarta: Departemen Pendidikan dan Kebudayaan.

www.banyuwangitourism.com | puter-kayun www.banyuwangibagus.com | tradisi-puterkayun-di-banyuwangi

banyuwangi.merdeka.com | riwayat-buyutjokso-dan-tradisi-puter-kayun-di-boyolangu 